\title{
Identification and Characterization of the Trichoderma harzianum Gene Encoding a-1,3-Glucanase Involved in Streptococcal Mutan Degradation
}

\author{
ADRIAN WIATER ${ }^{1^{*}}$, MONIKA JANCZAREK ${ }^{2}$, MAŁGORZATA PLESZCZYŃSKA $^{1}$ \\ and JANUSZ SZCZODRAK ${ }^{1}$ \\ ${ }^{1}$ Department of Industrial Microbiology, Institute of Microbiology and Biotechnology, \\ Maria Curie-Skłodowska University, Lublin, Poland \\ ${ }^{2}$ Department of Genetics and Microbiology, Institute of Microbiology and Biotechnology, \\ Maria Curie-Skłodowska University, Lublin, Poland
}

Received 3 August 2011, revised 26 September 2011, accepted 29 September 2011

Abstract

$\alpha-1,3$-Glucanases (mutanases) are currently of great interest due to their potential use in the field of dental care. These enzymes have been reported in several bacteria, yeasts and fungi, but up to now, characterization of this family of proteins has been relatively poor. In this study, we identify and characterize a mutanase gene from Trichoderma harzianum CCM F-340. Sequence analysis, on the nucleotide and amino acid levels reveals that this $\alpha$-1,3-glucanase is highly homologous to $\alpha$-1,3-glucanases from $T$. harzianum isolate CBS 243.71 and T. asperellum CECT 20539. T. harzianum CCM F-340 mutanase is a 634-aa residue protein with a calculated molecular mass of $67.65 \mathrm{kDa}$, composed of two distinct, highly conserved domains (a long N-terminal catalytic domain and a short C-terminal polysaccharide-binding domain) separated by a less conserved Pro-Ser-Thr-rich linker region. The mutanase gene was expressed in an E. coli BL21(DE3) host, under the transcriptional control of T7 promoter. The purified enzyme migrated as a band of about $68 \mathrm{kDa}$ after SDS-polyacrylamide gel electrophoresis, which coincided with the predicted size based on the amino acid sequence. Our data indicate that this enzyme is highly conserved in Trichoderma and can be produced in active form in such heterologous expression system.

Ke y words: Trichoderma harzianum, $\alpha$-1,3-glucanase, cloning, expression, mutanase

\section{Introduction}

Fungal species of the Trichoderma genus are soilborne, green-spored ascomycetes, found all over the world (Schuster and Schmoll, 2010). Trichoderma spp. have been used as biological control agents against a wide range of phytopathogenic fungi for many years (Papavizas, 1985), Trichoderma harzianum being especially effective. After host recognition, Trichoderma spp. attach themselves to the host hyphae via coiling, and penetrate the cell wall by secreting cell wall-degrading enzymes (CWDEs) (Viterbo et al., 2002). One of these enzymes, $\alpha$-1,3-glucanase, a so-called mutanase, is also a useful tool in dentistry.

Mutanases (exo- $\alpha-1,3$-glucanase: E.C. 3.2.1.84; endo$\alpha-1,3$-glucanase: E.C. 3.2.1.59), both fungal and bacterial, have the ability to hydrolyse $\alpha$-1,3-glucosidic bonds in streptococcal mutans and to remove dental as well as denture plaques (Budtz-Jörgensen and Kelstrup, 1977; Inoue et al., 1990). Therefore, mutanases could be applied as active ingredients in mouthwash, toothpaste, dental gel or chewing gum to prevent the accumulation of glucose biopolymers. Mutanases might be useful in preventive oral hygiene, but their molecular characterization is limited. Previously, mutanases have been reported in bacteria, such as Bacillus circulans (Matsuda et al., 1997), Paenibacillus spp. (Pleszczyńska et al., 2007), Flavobacterium spp. (Ebisu et al., 1975) and Microbispora rosea (Chung et al., 2001); yeasts, such as Schizosaccharomyces pombe (García et al., 2005), Endomyces tetrasperma (Meyer and Phaff, 1977), Cryptococcus albidus (Meyer and Phaff, 1977) and Rhodotorula minuta (Meyer and Phaff, 1977); and filamentous fungi, such as Aspergillus nidulans (Wei et al., 2001), Cladosporium resinae (Walker and Hare, 1977), Penicillium purpurogenum (Fuglsang et al., 2000; Shalom et al., 2008), Penicillium funiculosum (Reese et al., 1972), Trichoderma asperellum (Sanz et al., 2005), Trichoderma viride (Hasegawa et al., 1969), Trichoderma harzianum (Wiater and Szczodrak, 2002) and Verticillium malthousei (Reese et al., 1972). Some microbial mutanase genes have been cloned in the past few years. Several

\footnotetext{
* Corresponding author: A. Wiater, Department of Industrial Microbiology, Maria Curie-Skłodowska University, Akademicka 19, 20-033 Lublin, Poland; phone/fax: +48 8153759 60; e-mail: adrianw2@wp.pl
} 
of these genes are from fungi, including A. nidulans (Wei et al., 2001), P.purpurogenum (Fuglsang et al., 2000; Shalom et al., 2008), T. asperellum (Sanz et al., 2005) and T.harzianum (Fuglsang et al., 2000; AitLahsen et al., 2001).

The aim of this study was cloning of the $a-1,3-$ glucanase gene from T. harzianum CCM F-340 and its expression in a heterologous Escherichia coli expression system using a T7 promoter. Certain properties of the heterologous expressed enzyme were also investigated.

\section{Experimental}

\section{Materials and Methods}

Strain cultivation. Trichoderma harzianum CCM F-340 (Czech Collection of Microorganisms, Brno, Czech Republic) isolate was cultivated in a liquid medium containing $10 \mathrm{~g} / \mathrm{l}$ peptone and $15 \mathrm{~g} / \mathrm{l}$ malt extract ( $\mathrm{pH}$ 6.0). The culture was maintained in this medium at $30^{\circ} \mathrm{C}$ for 14 days without shaking. An E. coli strain TOP10F' (F- mcrA $\Delta$ (mrr-hsdRMS-mcrBC)

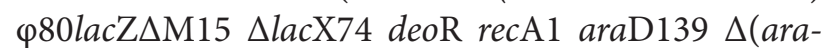
leu)7697 galU galK rpsL (Str ${ }^{\mathrm{R}}$ ) end $\mathrm{A} 1$ nupG) (Invitrogen, USA) was used as a host for plasmid construction and cultivated in LB medium ( $10 \mathrm{~g} / \mathrm{l}$ peptone, $5 \mathrm{~g} / \mathrm{l}$ yeast extract, $10 \mathrm{~g} / \mathrm{l} \mathrm{NaCl}, \mathrm{pH}$ 7.0). For E. coli derivatives harboring plasmids pJET1.2 and pET15b, the LB medium was supplemented with ampicillin $(100 \mu \mathrm{g} / \mathrm{ml})$. The expression strain E. coli BL21(DE3) plysS (F-, omp T, $h s d \mathrm{~S}_{\mathrm{B}}\left(\mathrm{r}_{\mathrm{B}}{ }^{-}, \mathrm{m}_{\mathrm{B}}{ }^{-}\right), d c m, g a l, \lambda(\mathrm{DE} 3)$, plysS, Cam $\left.{ }^{\mathrm{R}}\right)$ (Novagen, USA) was cultivated as described in the "Expression of the recombinant $T$. harzianum $\alpha$-1,3-glucanase" section (see below).

DNA methods and sequence analysis. Standard techniques were used for genomic and plasmid DNA isolation, agarose gel electrophoresis, restriction enzyme digestion, cloning and transformation (Sambrook et al., 1989). For standard PCR amplifications, DNA polymerase (Hypernova, Poland) was used. Sequencing was performed using the BigDye terminator cycle sequencing kit (Applied Biosystems, UK) and the ABI Prism 310 sequencer. Database searches were conducted with the BLAST and FASTA programs available at the National Center for Biotechnology Information (Bethesda, USA) and the European Bioinformatic Institute (Hinxton, UK). For phylogenetic tree construction, sequences of mutanases from T. harzianum and other related organisms were aligned using ClustalX software. Phylogenetic analysis was performed using the PhyML 3.0 program for maximum likelihood analysis.

Gene isolation. After 14 days of T. harzianum growth, total RNA from the microorganism pellet was isolated using the Total RNA isolation kit (A\&A Bio- technology, Poland) according to the manufacturer's instructions. The isolated RNA was used in reverse transcription reaction where oligo $(\mathrm{dT})_{15}$ served to prime the synthesis of the first cDNA strand. On the basis of the N-terminal amino acid sequence of the native mutanase from T.harzianum, degenerated primer TrihN1 (5'-GTIIIICAYTTYTTYATGATHATHGTIGGIGGIGAY-3') was designed. RT-PCR reaction was performed on the template of $1 \mu \mathrm{g}$ total RNA using the set of primers TrihN1-terminal and oligo $(\mathrm{dT})_{15}$ and a SMART cDNA library construction kit (Clontech, USA). PCR reaction was set in the mixture containing: $0.2 \mu \mathrm{M}$ of TrihN1 and oligo(dT) ${ }_{15}$ primers, $0.2 \mu \mathrm{g}$ of cDNA, $250 \mu \mathrm{M}$ of each dNTP, $1 \mathrm{U}$ of DNA polymerase (Hypernova, Poland) in $1 \times$ PCR buffer $(20 \mathrm{mM}$ Tris$\mathrm{HCl} \mathrm{pH} \mathrm{8.8,} 10 \mathrm{mM} \mathrm{KCl}, 3.4 \mathrm{mM} \mathrm{MgCl}_{2}, 0.15 \%$ Triton $\mathrm{X}-100$ ). The reaction mixture was incubated for $3 \mathrm{~min}$ at $95^{\circ} \mathrm{C}$, followed by 30 cycles at $95^{\circ} \mathrm{C}$ for $1 \mathrm{~min}, 60^{\circ} \mathrm{C}$ for $1 \mathrm{~min}, 72^{\circ} \mathrm{C}$ for $2 \mathrm{~min}$, and a final incubation for $5 \mathrm{~min}$ at $72^{\circ} \mathrm{C}$ using a Mastercycler Gradient (Eppendorf, Germany). The resulting PCR product was subcloned into pJET1.2 vector (CloneJet kit, Fermentas, Lithuania) giving plasmid pJET1.2T1, and the insert of this plasmid was sequenced.

On the basis of the obtained DNA sequence for mutanase gene, more specific primers Trih2 (5'-CTGG GCAGGGCGGTTGGCGTAC-3') and Trih3 (5'-GGA GCCTGCAGCAGA GCGCAACGC-3') were designed to synthesize the first cDNA strand with the leader sequence of the gene. These primers were used instead of the oligo(dT) ${ }_{15}$ primer. All further manipulations were performed with a SMART cDNA library construction kit (Clontech, USA) according to manufacturer's instruction. The first cDNA strand was synthesized using the SmartIV oligonucleotide (5'-AAGCAGTG GTATCAACGCAGAGTGGCCATTACGGCCGGG-3') and the Trih2 primer. Then, dsDNA synthesis was performed using the primer pair: 5'PCR (5'-AAGCAGTG GTATCAACGCAGAGT-3') and the Trih2 in the PCR mixture containing $0.2 \mu \mathrm{M}$ of each primer, $0.2 \mu \mathrm{g}$ of the first strand cDNA, $250 \mu \mathrm{M}$ of each dNTP, $1 \mathrm{U}$ of DNA polymerase in $1 \times \mathrm{PCR}$ buffer $(20 \mathrm{mM}$ Tris- $\mathrm{HCl}$, $\mathrm{pH} 8.8$, $10 \mathrm{mM} \mathrm{KCl}, 3.4 \mathrm{mM} \mathrm{MgCl}_{2}, 0.15 \%$ Triton X-100). The reaction mixture was incubated for $3 \mathrm{~min}$ at $95^{\circ} \mathrm{C}$, followed by 30 cycles at $95^{\circ} \mathrm{C}$ for $1 \mathrm{~min}, 60^{\circ} \mathrm{C}$ for $1 \mathrm{~min}$, $72^{\circ} \mathrm{C}$ for $1 \mathrm{~min}$, and a final incubation for $5 \mathrm{~min}$ at $72^{\circ} \mathrm{C}$. The PCR product ( $447 \mathrm{bp}$ ) containing cDNA with the signal sequence for mutanase was subcloned into pJET1.2, resulting in pJET1.2T2A plasmid, and sequenced. In addition, in order to determine the possible presence of introns in the native mutanase gene, genomic DNA fragment encoding the discontinuous gene was isolated. The genomic DNA was isolated from cell pellet by use of Yeast Genomic DNA isolation kit (A\&A Biotechnology, Poland). PCR reaction 
was carried out using T.harzianum genomic DNA as a template and oligonucleotide primers Trih3B (5'-GCTTCTTCTGCTGACCGTCTCGTATTC-3') and Trih4H (5'-TTTTAAGCTTCTAGCAGTATTGACAT GCCGTTGGCGGG-3'). The cycle conditions for this reaction mixture were the same as for the primer pair: TrihN1 and oligo $(\mathrm{dT})_{15}$. The resulting PCR product (2200 bp) was subcloned into pJET1.2 vector giving pJET1.2T2 plasmid, and sequenced. The presence of introns in the mutanase gene was determined after a comparison of the full-length gene sequence with its cDNA sequence.

Expression plasmid construction. The T. harzianum mutanase gene without the leader sequence was PCR amplified by using as a template the pJET1.2T1 plasmid and a set of primers: Trih4H (5'-TTTTAAGCTTCTA GCAGTATTGACATGCCGTTGGCGGG-3') and Trih5 (5'-ATGGCTTCTTCTGCTGACCGTCTCGTAT TC-3'). PCR amplification was set in mixture containing $0.2 \mu \mathrm{M}$ of each primer, $0.2 \mu \mathrm{g}$ pJET1.2T1, $250 \mu \mathrm{M}$ of each dNTP, $1 \mathrm{U}$ of DNA polymerase in $1 \times \mathrm{PCR}$ buffer (20 mM Tris- $\mathrm{HCl}, \mathrm{pH} 8.8,10 \mathrm{mM} \mathrm{KCl}, 3.4 \mathrm{mM} \mathrm{MgCl}_{2}$, $0.15 \%$ Triton $\mathrm{X}-100)$. The reaction mixture was incubated at the same temperature conditions as mentioned above for the primer pair: Trih3B and Trih4H. The 1849-bp-long amplicon was digested with HindIII endonuclease and cloned into HindIII site and previously filled with Klenow polymerase NcoI site of pET15b vector (Novagen, USA). The resulting pET15bTM recombinant vector was transformed into competent cells of E. coli BL21(DE3) plysS strain (Novagen, USA) using a standard procedure (Sambrook et al., 1989).

Expression of the recombinant T. harzianum a-1,3glucanase. An E. coli BL21(DE3) plysS strain harboring the pET15bTM recombinant plasmid was grown overnight in LB broth containing $1 \%$ of glucose supplemented with ampicillin $(100 \mu \mathrm{g} / \mathrm{ml})$ at $37^{\circ} \mathrm{C}$ in an air shaker at $220 \mathrm{rpm}$. Expression broth (1\% tryptone, $0.5 \%$ yeast extract, $1 \% \mathrm{NaCl}$ ) containing the same antibiotic was inoculated with the preculture $(1 \%$, v/v). Cultivation was continued at $37^{\circ} \mathrm{C}$ to $\mathrm{OD}_{600}$ of 0.3 . Then, the culture was supplemented with isopropyl- $\beta-\mathrm{D}-1-$ thiogalactopyranoside (IPTG) (Gold Biotechnology, USA) to $1 \mathrm{mM}$ final concentration. The expression from E. coli BL21(DE3) plysS containing pET15bTM was performed at $16^{\circ} \mathrm{C}$ for $16 \mathrm{~h}$ on a rotary shaker at $220 \mathrm{rpm}$. The expression of the $\alpha$-1,3-glucanase gene at higher temperatures did not result in the synthesis of the target protein (data not shown).

Purification of the recombinant T.harzianum $\boldsymbol{\alpha}$-1,3-glucanase. After $\boldsymbol{\alpha}$-1,3-glucanase expression in an $E$. coli host, cells were harvested by centrifugation at $5000 \times \mathrm{g}$ for $20 \mathrm{~min}$, the cell pellet was resuspended in $50 \mathrm{ml}$ of buffer $\mathrm{A}\left(20 \mathrm{mM} \mathrm{K}_{2} \mathrm{HPO}_{4}-\mathrm{KH}_{2} \mathrm{PO}_{4}\right.$, pH 7.5, $50 \mathrm{mM} \mathrm{KCl}$ ) and frozen at $-20^{\circ} \mathrm{C}$ for $15 \mathrm{~min}$. After thawing at room temperature, the samples were sonicated $(6 \times 30 s$ with $59 \mathrm{~s}$ intervals on ice, Sonics VibraCell VCX 130) and centrifuged at $10000 \times \mathrm{g}$ for $30 \mathrm{~min}$. The supernatant containing the desired protein was applied onto anion exchange resin DEAE-Sepharose (GE Life Science, Sweden) equilibrated with four volumes of buffer A. The protein was collected as the flow-through fraction. The mutanase present in this fraction was under pressure concentrated 10-times by membrane filters MWCO 30000 (Vivaflow2, Sartorious $\mathrm{GmbH}$, Germany). The protein was then purified by gel filtration (Size Exclusion Chromatography) (SephadeX 200 26/200 on a column equilibrated with buffer D (20 mM KH $\mathrm{PO}_{4}-\mathrm{K}_{2} \mathrm{HPO}_{4}, 150 \mathrm{mM} \mathrm{KCl}, \mathrm{pH}$ 7.5) (GE Life Science, Sweden). The fraction containing the purified protein was collected and lyophilized.

Enzyme activity assay and determination of protein concentration. The recombinant enzyme was analysed for its acitivity in mutan hydrolysis by a modified Wiater et al. (2008) method as described previously, where $0.1 \%(\mathrm{w} / \mathrm{v})$ mutan was used as a substrate in the hydrolysis reaction carried out in $50 \mathrm{mM}$ acetate buffer solution ( $\mathrm{pH} 5.5$ ) at $37^{\circ} \mathrm{C}$ for 1 hour. The protein concentration was assessed by the Bradford method (Bradford, 1976), using bovine serum albumin as standard, with absorbance measured at $595 \mathrm{~nm}$.

\section{Results and Discussion}

Isolation of T. harzianum $\alpha$-1,3-glucanase gene and construction of the expression plasmid. In order to isolate the $\alpha$-1,3-glucanase gene from the Trichoderma harzianum CCM F-340 genome, degenerate primer TrihN1 was designed, based on the $\mathrm{N}$-terminal amino acid sequence of the enzyme produced by the isolate. The corresponding 5'-end of the mutanase gene primer and oligo $(\mathrm{dT})_{15}$ primer were used in RT-PCR reaction with total RNA of T. harzianum to obtain cDNA of the mutanase gene without introns or leader sequence. The obtained PCR product was cloned into pJET1.2 vector resulting in pJET1.2T1 plasmid, and was then sequenced. Based on the sequence of this DNA fragment, additional reverse Trih2 and forward Trih22 primers were designed. A DNA fragment containing the leader sequence of the gene was obtained using these primers and SMART technology from Clontech. A fulllength mutanase gene termed mut $A W$ was obtained by combining sequences of these two PCR fragments.

To investigate whether the mutanase gene from T. harzianum CCM F-340 isolate contained introns, DNA fragment containing the full-length gene was amplified by PCR from the organism's genomic DNA. The comparison of this sequence with the sequence of the mutanase cDNA revealed the presence of 
two introns. They were 52-bp and 43-bp in length, at 570 bp (intron 1), sequence: 5'-TAAGTCGCAACTTTAGAGTCGAGAGCAGGGGAGCAATACTGATGTCTTTATA-3'; and at 1778 bp (intron 2), sequence: 5'-GCCCCCATAACCCTTACTTGCTTCCTTAACTAATCCTTCATAG-3', respectively. The nucleotide sequence of mutAW and the deduced amino acid sequence of the mutanase from T.harzianum CCM F-340 are presented in Figure 1.

The entire mutanase-encoding gene is 2000-bp long while the cDNA lacking both introns contains a 1905-bp open reading frame initiating with an ATG codon and terminating with TAA stop codon at nucleotide position 1903. It encodes a protein of 634 amino acids. The first 111 nucleotides at 5'-end of the gene are predicted to encode a 37-aa-long signal peptide. The sequence of the T. harzianum CCM F-340 mutanase gene mutAW has been deposited in the GenBank database (accession no HQ871941). The molecular mass for the proenzyme calculated from the amino acid sequence and of the mature enzyme was $67.65 \mathrm{kDa}$ and $63.86 \mathrm{kDa}$, respectively. Based on the amino acid sequence, the isoelectric point of the mutanase was estimated to be 5.68 .

The nucleotide sequence of the T. harzianum CCM F-340 mutAW was analyzed and aligned with sequences of homologous genes available at GeneBank (Fig. 2). The gene displayed $97.6 \%$ identity to the deposited sequence of a mutanase gene from another T.harzianum isolate CBS 243.71 (accession no AJ243799), 96.2\% identity to a homologous gene from Hypocrea lixii (accession no HC050999), 82.8\% identity to T. asperellum homolog (accession no AJ784420) and $72.7 \%$ identity to P. purpurogeum mutA gene (accession no EU341820). The amino acid sequence of the protein encoded by the T.harzianum mutAW gene shared significant homology with proteins belonging to the glycohydrolase-71 superfamily, corresponding to the family of $\alpha$-1,3-glucanases. MutAW protein showed the highest sequence homology (98\% identity and 99\% similarity, respectively) to the mutanase of T. harzianum isolate CBS 243.71 (accession no. CAC80493) (Fig. 2). A lower homology of this protein to $\alpha$-1,3-glucanases from T. asperellum (88\% identity and 94\% similarity) (accession no CAH04820), Penicillium marneffei ATCC 18224 (60\% identity and 71\% similarity) (accession noEEA20869) and P.purpurogenum (56\% identity and $70 \%$ similarity) (accession no AAF27912) was observed. The sequence analysis revealed that T. harzianum CCM F-340 mutanase contains two distinct domains: C-terminal domain responsible for binding of the polysaccharide substrate (mutan) and a long N-terminal catalytic domain. This finding concurs with the data described by Fuglsang et al. (2000), where authors demonstrated that mutanases from T. harzianum CBS 243.71 and P. purpurogenum CBS 238.95 are composed of two distinct domains: a N-terminal catalytic domain and C-terminal polysaccharide-binding domain, separated by an O-glycosylated Pro-Ser-Thr-rich linker peptide. Similarly to the T.harzianum CCM F-340 mutanase gene identified by us, $\alpha$-1,3-glucanase cDNA from T. harzianum CBS 243.71 encoded a 634-aa-residues protein with 37 -aa-long signal peptide. In contrast, $P$. purpurogenum CBS 238.95 mutanase gene contained four introns and its compiled coding sequence encoded a protein of 630 aa, with 30 -aa signal peptide (Fuglsang et al., 2000). On the other hand, cDNA for mutanase from another isolate of $P$. purpurogenum CBS 257.37 was only 1803-bp long and encoded a protein of 600 aa (63.5 kDa) (Shalom et al., 2008), demonstrating a significant diversity among mutanase genes on both the genomic and protein levels. The N-terminal catalytic domain of T. harzianum mutanase encompasses most of the protein length (region 1-453 aa). However, the mutan-binding C-terminal domains of the enzymes from these two species are relatively short and contain two regions of internal similarity (Fig. 2) (Fuglsang et al., 2000). In T.asperellum genome agn13.2 gene was identified and shown to encode $\alpha$-1,3-glucanase of 635 aa (Sanz et al., 2005). The coding sequence of A. nidulans mutA gene homologous to T.harzianum CCM F-340 mutAW was interrupted by three introns and encoded a protein of 642 aa with predicted N-terminal 22-aa-long secretion signal. It was established that the mutA gene was expressed in this organism during sexual development (Wei et al., 2001).

Using the amino acid sequences of several mutanases available from Genbank, we performed a phylogenetic analysis of Trichoderma species and other closely related genera (Fig. 3). In general, the compared $\alpha-1,3-$ glucanases from different Trichoderma species and the other closely related organisms demonstrate significant diversity with respect to the amino acid sequence length and the level of homology. The constructed tree shows that the microorganisms from T.harzianum form a tight cluster and are most closely related to T. asperellum species (Fig. 3) (Sanz et al., 2005). Among other analyzed organisms, T. harzianum mutanase was the most similar to those of Neurospora crassa, P. chrysogenum and Aspergillus flavus, but more different from those of A. nidulans, P. purpurogenum, P. marneffei and Talaromyces stipitatus (Fig. 3) (Fuglsang et al., 2000; Wei et al., 2001).

Expression and purification of the recombinant T. harzianum a-1,3-glucanase. In nature, T. harzianum produces and secretes the mutanase to the environment upon induction by $a-1,3$-glucan. To produce this enzyme at a constitutive level, independent of such inductors, a recombinant mutanase was generated in the E. coli BL21(DE3) plysS expression system. For this purpose, the DNA fragment containing the 


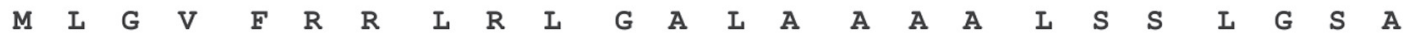

1 ATGTTGGGCG TTTTCCGCCG CCTCAGGCTC GGCGCCCTTG CCGCCGCAGC TCTGTCTTCT CTCGGCAGTG $\begin{array}{lllllllllllllllllllllll}\text { A } & \text { P } & \text { A } & \text { N } & \text { V } & \text { A } & \text { I } & \text { R } & \text { S } & \text { L } & \text { E } & \text { E } & \text { R } & \text { A } & \text { S } & \text { S } & \text { A } & \text { D } & \text { R } & \text { L } & \text { V } & \text { F } & \text { C }\end{array}$ 71 CCGCTCCCGC CAATGTTGCT ATTCGGTCTC TCGAGGAACG TGCTTCTTCT GCTGACCGTC TCGTATTCTG $\begin{array}{lllllllllllllllllllllll}H & F & M & I & G & I & V & G & D & R & G & S & S & A & D & Y & D & D & D & M & Q & R & A\end{array}$

141 TCACTTCATG ATTGGTATCG TTGGTGATCG TGGCAGCTCG GCAGACTATG ATGACGATAT GCAACGTGCC $\begin{array}{llllllllllllllllllllllllll}K & A & A & G & I & D & A & F & A & \text { L } & \text { N } & \text { I } & G & \text { V } & \text { D } & G & Y & \text { T } & \text { D } & \text { Q } & \text { Q } & \text { L } & G & Y\end{array}$ 211 AAAGCCGCTG GCATTGACGC CTTCGCCCTG AACATCGGCG TTGACGGCTA TACCGACCAG CAGCTCGGAT $\begin{array}{lllllllllllllllllllllll}A & Y & D & S & A & D & \text { R } & \text { N } & G & \text { M } & \text { K } & \text { V } & \text { F } & \text { I } & \text { S } & \text { F } & \text { D } & \text { F } & \text { N } & \text { W } & \text { W } & \text { S } & \text { P }\end{array}$ 281 ATGCCTATGA CTCTGCCGAT CGTAATGGCA TGAAATCTT CATCTCATTC GATTTCAATT GGTGGAGCCC $\begin{array}{lllllllllllllllllllllllll}G & N & A & V & G & V & G & Q & K & I & A & Q & Y & A & N & R & P & A & Q & \text { L } & Y & V & D\end{array}$

351 CGGCAATGCA GTTGGTGTTG GCCAGAAGAT TGCGCAGTAC GCCAACCGCC CTGCCCAGCT GTATGTCGAC

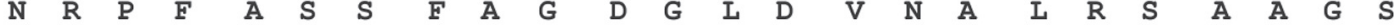

421 AACCGACCAT TCGCCTCTTC CTTCGCCGGT GACGGTCTAG ATGTAAATGC GTTGCGCTCT GCTGCAGGCT

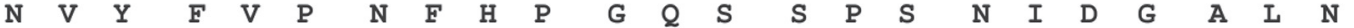

491 CCAACGTTTA CTTTGTTCCC AACTTCCACC CTGGCCAATC TTCTCCCTCA AACATTGATG GTGCCCTTAA W $M$ A Intron 1

561 CTGGATGG G TAGTCGCAAC TTAGAGTCGA GAGCAGGGA GCAATACTGA TGTCTTTATA G

622

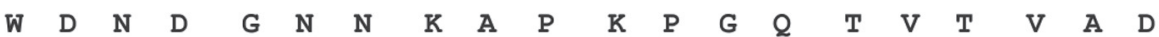

C TGGgATAATG ATGGAAACAA CAAGGCACCC AAGCCGGGCC AGACTGTCAC GGTGGCAGAC $\begin{array}{lllllllllllllllllllllllll}G & D & N & A & Y & K & N & \text { W } & \text { L } & G & G & K & P & Y & \text { L } & \text { A } & \text { P } & \text { V } & \text { S } & \text { P } & \text { W } & F & F & T\end{array}$ 683 GGTGACAACG CTTACAAGAA TTGGTTGGGT GGCAAGCCTT ACCTAGCGCC TGTCTCACCT TGGTTTTTTA $\begin{array}{lllllllllllllllllllllllll}H & F & G & P & E & V & S & Y & S & K & N & W & V & F & P & G & G & P & I & I & Y & N & R\end{array}$ 753 CCCATTTCGG CCCCGAAGTT TCATACTCCA AGAACTGGGT CTTCCCAGGT GGTCCTCTGA TCTACAACCG $\begin{array}{llllllllllllllllllllllll}W & Q & Q & V & \text { L } & Q & Q & G & G & F & P & M & V & E & I & V & T & W & N & D & Y & G & E & S\end{array}$

823 GTGGCAACAG GTCTTGCAGC AGGGCTTCCC CATGGTTGA ATCGTTACCT GGAATGACTA CGGCGAGTCT $\begin{array}{llllllllllllllllllllllllll}H & Y & \text { V } & G & \text { P } & \text { L } & \text { K } & \text { S } & \text { K } & \text { H } & \text { F } & \text { D } & \text { D } & \text { G } & \text { N } & \text { S } & \text { K } & \text { W } & \text { V } & \text { N } & \text { D } & \text { M } & \text { P } & \text { H }\end{array}$ 893 CACTACGTCG GTCCACTAAA GTCTAAGCAT TTCGATGATG GCAACTCCAA ATGGGTCAAT GATATGCCCC $\begin{array}{lllllllllllllllllllllll}D & G & F & \text { L } & \text { D } & \text { L } & \text { S } & K & \text { P } & \text { F } & \text { I } & \text { A } & \text { A } & \text { Y } & \text { K } & \text { N } & R & \text { D } & \text { T } & \text { D } & \text { I } & S & K\end{array}$ 963 ATGATGGATT CCTGGATCTT TCAAAGCCGT TTATTGCTGC GTATAAGAAC AGGGATACCG ACATCTCCAA

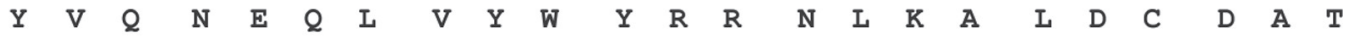

1033 GTATGTTCAA AATGAGCAGC TTGTTTACTG GTACCGCCGC AACTTGAAGG CATTGGACTG CGACGCCACC $\begin{array}{llllllllllllllllllllllllll}D & T & T & S & N & R & P & A & N & N & G & S & G & N & Y & F & M & G & R & P & D & G & W & Q\end{array}$ 1103 GACACCACCT CTAACCGTCC AGCTAATAAC GGAAGTGGTA ATTACTTTAT GGGACGTCCT GATGGTTGGC $\begin{array}{lllllllllllllllllllllll}T & M & D & D & T & V & Y & V & A & A & \text { L } & \text { L } & K & \text { T } & \text { A } & G & \text { S } & \text { V } & \text { T } & \text { V } & \text { T } & \text { S } & G\end{array}$

1173 AAACTATGGA TGACACCGTT TATGTTGCCG CACTTCTCAA GACTGCCGGT AGCGTCACTG TCACGTCTGG $\begin{array}{lllllllllllllllllllllll}G & T & T & Q & T & F & Q & A & N & A & G & A & N & L & F & Q & I & P & A & S & I & G & Q\end{array}$

1243 CGGCACCACT CAAACGTTCC AGGCCAACGC CGGAGCCAAC CTCTTCCAAA TCCCAGCCAG CATCGGCCAG

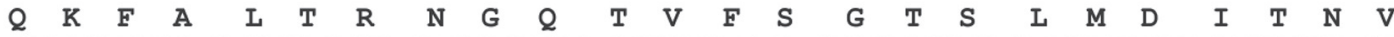
1313 CAAAAATTCG CTCTAACTCG CAATGGTCAG ACCGTCTTTA GTGGAACCTC ATTGATGGAT ATCACCAACG $\begin{array}{llllllllllllllllllllllll}C & S & C & G & I & Y & & N & F & N & P & Y & V & G & \text { T } & \text { I } & P & A & G & F & D & D & P & L\end{array}$

1383 TTTGCTCTTG CGGTATCTAC AACTTCAACC CATATGTTGG CACCATTCCT GCCGGCTTTG ACGACCCTCT $\begin{array}{llllllllllllllllllllllll}Q & A & D & G & L & F & S & \text { L } & T & I & G & L & H & V & T & T & C & Q & A & K & P & S & L\end{array}$ 1453 ACAGGCTGAT GGTCTTTTCT CTTTGACCAT CGGATTGCAT GTCACAACTT GTCAGGCCAA GCCATCTCTT $\begin{array}{lllllllllllllllllllllllll}G & T & N & P & P & V & T & S & G & P & V & S & S & L & P & A & S & S & T & T & R & A & S & S\end{array}$ 1523 GGAACCAACC CTCCTGTCAC TTCCGGCCCT GTGTCCTCGC TTCCAGCTTC CTCCACCACC CGCGCATCCT $\begin{array}{lllllllllllllllllllllll}\mathbf{P} & \mathrm{P} & \mathrm{P} & \mathrm{V} & \mathrm{S} & \mathrm{S} & \mathrm{T} & \mathrm{R} & \mathrm{V} & \mathrm{S} & \mathrm{S} & \mathrm{P} & \mathrm{P} & \mathrm{V} & \mathrm{S} & \mathrm{S} & \mathrm{P} & \mathrm{P} & \mathrm{V} & \mathrm{S} & \mathrm{R} & \mathrm{T} & \mathrm{S}\end{array}$

1593 CGCCGCCTCC TGTTTCTTCC ACTCGTGTCT CTTCTCCCCC TGTCTCTTCC CCTCCAGTTT CTCGCACCTC $\begin{array}{lllllllllllllllllllllll}S & T & P & P & P & A & S & S & T & P & P & S & G & Q & V & C & V & A & G & T & V & A & D\end{array}$

1663 TTCCACTCCC CCTCCAGCGA GCAGCACGCC GCCATCGGGT CAGGTTTGCG TTGCCGGTAC CGTTGCTGAC $\begin{array}{llllllllllllllllllllll}G & E & S & G & N & Y & I & G & L & C & Q & F & S & C & N\end{array}$

1733 GGCGAGTCTG GCAACTACAT CGGCCTGTGC CAATTCAGCT GCAAqGTCCC CATAACCCTT ACTTGCTTCC

Intron 2

1803 TTAAC TAATC CTTCATA N P CCACCAGGAC CGTGTAAGTG CACCGCCTTT GGTGCTCCCA 1873 TCAACCCACC GGCAAGCAAT GGCCGCAACG GCTGCCCTCT GCCGGGAGAA GGCGATGGTT ATCTGGGCCT $\begin{array}{llllllllllllllllllllllllll}C & S & F & S & C & N & H & N & Y & C & P & P & T & A & C & Q & Y & C & *\end{array}$

1943 GTGCAGTTTC AGTTGTAACC ATAATTACTG CCCCCCAACG GCATGTCAAT ACTGCTAAGA GAGAGATCAA 2013 TCTTAGTATG AGTATATGGA GGCTGCCGAA GGACCAGTTA GCTGTTCTTA TCGGTAGACG AAACCCATAG 2083 AGCAAGAAGT TAAATAAAAT GCAATTAATT TGTTGTCAAT TCTGGTTGCA TATACATGTA TATACCCTGA 2157 ACATCATAAC ACCCTCCCCG GAT

Fig. 1. The nucleotide sequence of the entire T. harzianum CCM F-340 mutAW gene.

Amino acid sequence of $\alpha$-1,3-glucanase is presented as a single letter code. The leader sequence encoding the signal peptide is underlined and the sequences of introns 1 and 2 in the full-length gene are marked by boxes. The putative linker Pro-Ser-Thr region is highlighted in grey. This sequence has been deposited in the GenBank database and its accession number is HQ871941. 
Signal peptide

(1) M---LGVFRRLRLGALAAAAALSSLGSAAPANVAIRSLEERASSADRLVFCHFMIGIVGDR

(1) M---LGVF'RRLRLGALAAAALSSLGSAAPANVAIRSLEERASSADRLVFCHFMIGIVGDR

(1) MIpkLNLVRRLGLGALAATALSSLSSAAPANIAIRSLEERASSADRLVFCHFMIGIVGDR

(1) M-----IVKGLFLAALSA--MSALVQGYPGQ--ERSLSERQST-DRLVFAHFMIGITSDR

(1) M--------KVSSAFAATLSAI IAACSA-LP SDSMVSRRSTSDRLVF AHFMVGIVSDR

T.h.

H.I.

T.a.

P.m.

P.p.

(58) GSSADYDDDMORAKAAGIDAFALNIGVDGYTDQQLGYAYDSADRNGMKVF ISFDFNWWSP

(58) GSSADYDDDMORAKAAGIDAFALNIGVDGYTDOQLGYAYDSADRNGMKVF ISFDFNWWSP

(61) GSSSDYDDDMORAKAAGIDAFALNIGVDGYTDQQLGFAYDSANRNGMKVF ISFDFNWWSP

(51) SSSADYDADMORAKSYGIDAFFALNIGVDPYTDOOLGFAYDSAARNGMKVF ISFDFNWWNT

(50) TSASDYDADMQGAKAYGIDAF ALNIGTDTFSDQQLGYAYESAANNDMKVF ISFDFNWWST

(118) GNAVGVGOKIAOYANRPAOLYVDNRPFASSFAGDGLDVNALRSAAGSNVYFVPNFHP GOS

(118) GNAVGVGOKIAOYANRPAOLYVDNRPFASSF AGDGLDVNALRSAAGSNVYFVPNF HPGOS

(121) GNAAGVGQKIAOYANLPAOLYVDNRVFASSF AGDGLDVNALRSAAGSNVYFVPNFHPGQS

(111) GOATAIGOKIAOYAGLPGOLKVDGKVFVSSF AGDGVNIGAMRSAAGVELFFAPNF HP SYG

(110) SQATEIGQKIAQYGSLPGQLMYDDKIFVSSF AGDGVDVAALKSAAGGNVFFAPNFHP SYG

T.h.

H.I.

T.a.

P.m.

P.p.

T.h.

H.I.

T.a.

P.m.

P.p.

(178) S-P SNIDGALNWMAWDNDGNNKAP KPGOTVTVADGDNAYKNWLGGKPYLAPVSP WFFTHF

(178) S-P SNIDGALNWMAWDNDGNNKAP KP GQTVTVADGDNAYKNWLGGKP YLAPVSTWVFNHF

(181) S-TSNIDGALNWMAWDNDGNNKAP KP GONVTVADGDNA YKSWLGSKP YLAAP ISP EFFTHF

(171) TDMSNVDGLLNWMGWP SNGNNKAP TSGATVSVEQGDNDYISALAGKAYIAPASP WF STHF

(170) TDLSDVDGLLNWMGWP SNGNNKAP TAGANVTVEEGDEEYITALDGKP YIAPASP WF STHF

T.h.

H.I.

T.a.

P.m.

P.p.

(237) GPEVSYSKNWVFPGGPLIYNRWOOVLOOGFPMVEIVTWNDYGESHYVGPLKSKHFDDGNS

T.h.

(237) GPEVSYSKNWVFP SGPLIYNRWOQVLQOGFP RVEIVTWNDY GE SHYVGP LKSKOFHDGNS

(240) GPEVSF SKNWVTP SGALIYNRWOOILOOGFPMVEIITWNDYGESHYVGP LKSKHYDDGNS

(231) GPEVSYSKNWVFP SDLLWYNRWOELLKLGPRF IEIVTWNDYGE SHY I GP LSSPHTDDGAS

(230) GPEVTYSKNWVFP SDLLFYQRWNDLLNLGPQF IEVVTWNDYGE SQYVGP LNSP HTDDGSS

H.I.

T.a.

P.m.

P.p.

(297) KWVNDMPHDGFLDLSKPFIAAYKNRDTDI-SKYVONEQLVYWYRRNLKALDCDATDTTSN

(297) KWVNDMP HDGFLDLSKPF IAAYKNRDTDI-SKYVONEOLVYWYRRNLKALDCDATDTTSN

(300) KWTNDMP HDGFLDLSKPF IAAYKNKDTDV-SKYIONEELVYWYRRNLKGLNCDATDTTYN

(291) KWVNDMP HDGWLDMAKPF IAAFKAGATTV-DNY ITNDELVYWYRPTLKNVNCDATDTCMN

(290) RWANDMP HDGWLDLAKPYIAAFHDGATSLSSSY ITEDQLIYWYRPQPRLMDCDATDTCM-

(356) RPANNGSGNYFMGRPDGWOTMDDTVYVAALLKTAGSVTVTSGGTTOTFOANAGANLFOIP

(356) RPANNGSGNYFEGRPDGWQTMDDTVYVAALLKTAGSVTVTSGGTTQTFQANAGANLFOIP

(359) RPANNASGNYFEGRPDGWETMDDDVYVAAFLKSAGTVTVTSGGTTQSFQGNAGANIFQVP

(350) PSASNSSGNYFLGRPNGYETMODSVFVVSLLTAPAQVTVTSGGNSOTFOASAGANAFOVP

(349) VAANNDTGNYFEGRPNGWE SMEDAVFVVALLQSAGTVQVTSGPNTETFDAPAGASAFQVP

T.h.

H.I.

T.a.

P.m.

P.p.

T.h.

H.I.

T.a.

P.m.

P.p.

(416) ASIGOOKFALTRNGOTVFSGTSLMDITNVCSCGIYNFNPYVGT IPAGFDDPLOADGLFSI

(416) ASIGQQKFALTRNGQTVFSGTSLMDITNVCSCGIYNFNPYVGT IPAGFDDPLQADGLFSI

(419) ASLGOQKFALTRNGOTVFSGVSLMDITDVCACGIYNFNTYVGTVPAGFDDPLQGDGLASI

(410) MGVGSQTFSVTRNGATVFQGTSLKQIINGCVCGLYNFNAYVGTLPAGFSDPLGPAGLASL

(409) MGFGPQSFSLSRDGETVLSGT SLKDIIDGCLCGIYNFNAYVGSLPATFSDPLEP PSLNAF

T.h.

H.I.

T.a.

P.m.

P.p.

(476) TIGLHVTTCQAKPSLG---TNPP--VTSGPVSSLPASSTTRASSPPPVSSTRVSSPPVSS

(476) TIGLHVTTCOAKPSLG---TNPP--VTSGPVSSLPASSTTRASSPP PVSSTRVSSPPVSS

(479) TIGLHVTTCQARPSLG---TNPP--VTSGPITSIPVSS-TQASS-PPVSSTHASSPPVSP

(470) VQGLHVATCAATPSLG---TAPP--VVTAP---------------PV-------PATTT

(469) SEGLKVSTCSATPSLGItsTTPPEtIPTGTIT--PGSAITGAATTTSTIST-TSTISTTS Mutan-binding domain

(531) PPVSRTSSTPPPA-SSTPP SGQVCVAGTVADGESGNY IGLCQF SCNYGYCP-----PGPC

(531) PPVSRTSSAPP PPGNSTPP SGQVCVAGTVADGESGNY I GLCQF SCNYGYCP-----P GPC

(532) PPSTSRSSSSTPP-VSTPP SGQVCVAGTVADGESGNY IGLCNF SCNYGYCP-----P GPC

(502) TTIITTKTTTTST--STSTSG-TCIAGT---G-PGNYVGLCSFCCNFGYCP-----P GPC

(526) TFISTTTTTTSSAATST-TTG-TCIAGT---G-PDNYSGLCSFCCNYGYCPgsdgsA_GPC

T.h.

H.I.

T.a.

P.m.

P.p.

T.h.

H.I.

T.a.

P.m.

P.p.

(585) KCTAFGAP INP PASNGRNGCP LPGEGDGYLGI CSFSCNHNYCP PTACOY-C

T.h.

(586) KCTAFGAPISP PASNGRNGCP LPGEGDGYLGLCSF SCNHNYCP PTACQY-C

(586) KCTAYGSPISP PATNGRNGCP LSGEGDGYLGLCSF SCNHGYCP PTACOY-C

(550) TCTAYGAPVPTPPVTGTVGLP LYNEDNSYLGLCSFACNHGYCPNTACRV-A

(580) TCTAYGDPVPTPPVTGTVGVP LDGEGDSYLGLCSFACNHGYCP STACQVES

H.I.

T.a.

P.m.

Pp.

Fig. 2. Aligment of the amino acid sequence of T. harzianum CCM F-340 a-1,3-glucanase (T.h.) with homologous sequences of H. lixii CECT 2413 (anamorh: T. harzianum) (accession no CAC80493) (H.l.), T.asperellum CECT 20539 (accession no CAH04880) (T.a.), P. marneffei ATCC 18224 (accession no EEA20869) (P.m.) and P.purpurogenum CBS 238.95 (accession no AF214481) (P.p.).

Amino acids identical to the T. harzianum CCM F-340 $\alpha$-1,3-glucanase sequence are shaded. The sequences for signal peptide, catalytic domain and mutan-binding domain are underlined. The two regions of internal similarity in the polysaccharide-binding domain are boxed. 


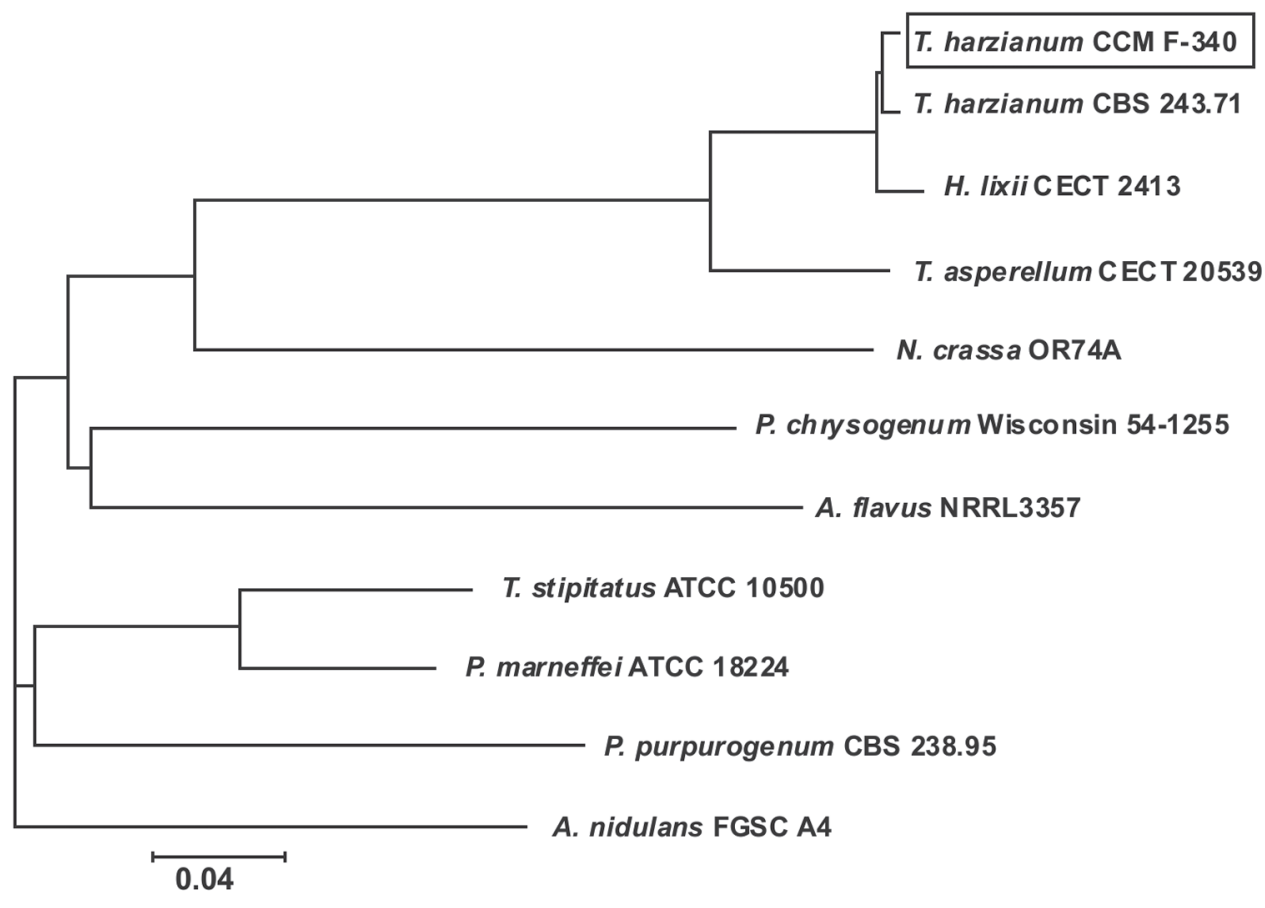

Fig. 3. Dendrogram showing the relationship between $\alpha-1,3$-glucanases from T. harzianum CCM F-340 and other closely related organisms.

The amino acid sequences of $\alpha$-1,3-glucanases used for phylogenetic tree construction were from T. harzianum CCM F-340 (accession no HQ871941), T. harzianum CBS 238.95 (accession no AAF27911), H. lixii CECT 2413 (accession no CAC80493), T. asperellum CECT 20539 (accession no CAH04880), N. crassa OR74A (accession no EAA29582), P. chrysogenum Wisconsin 54-1255 (accession no CAP80960), T. stipitatus ATCC 10500 (accession no EED20417), Penicillium marneffei ATCC 18224 (accession no EEA20869), P. purpurogenum CBS 238.95 (accession no AF214481), A. flavus NRRL3357 (accession no EED56220), A. nidulans FGSC A4 (accession no CBF84404).

coding region for the T. harzianum mutanase without the signal peptide, was PCR amplified, digested with HindIII endonuclease, and cloned into HindIII site and previously blunted after digestion NcoI site of a pET15b expression vector. The resulting plasmid, pET15bTM, allowed the production of high levels of the recombinant mutanase using a T7 promoter (Fig. 4).

The pET15bTM plasmid was used to transform the E. coli BL21(DE3) plysS host and the expression of the mutanase gene was monitored as described in the Experimental section. Trials were conducted at several different temperatures and it was observed that the most effective enzyme production occurred when the temperature was lowered to $16^{\circ} \mathrm{C}$ (data not shown). To purify the recombinant enzyme, after expression, cells were suspended in buffer $\mathrm{A}$, frozen and lysed by sonication. Insoluble fractions were separated by centrifugation and the supernatant was applied to a weak DEAE anionic resin previously equilibrated with buffer A. The protein was collected as the flow-through fraction. This fraction was condensed by diafiltration. In the next step, the enzyme was purified by molecular sieving as described in the Experimental section. Results for recombinant $\alpha$-1,3-glucanase purification are summarized in Table I. The resulting protein had a molecular mass of $\sim 68 \mathrm{kDa}$, which was in congruence with the theoretical molecular mass $(63.86 \mathrm{kDa})$ based on the amino acid sequence. Furthermore, the recombinant $\alpha$-1,3-glucanase possesses a mutanolytic activity $(0.097 \mathrm{U} / \mathrm{mg}$ protein). Figure 5 illustrates the activity of the recombinant mutanase in the streptococcal mutan degradation in the agar plate test. The mutan-removing effect of mutanase was significant, but lower than in its natural genetic background under inducible conditions (Wiater et al., 2008). The

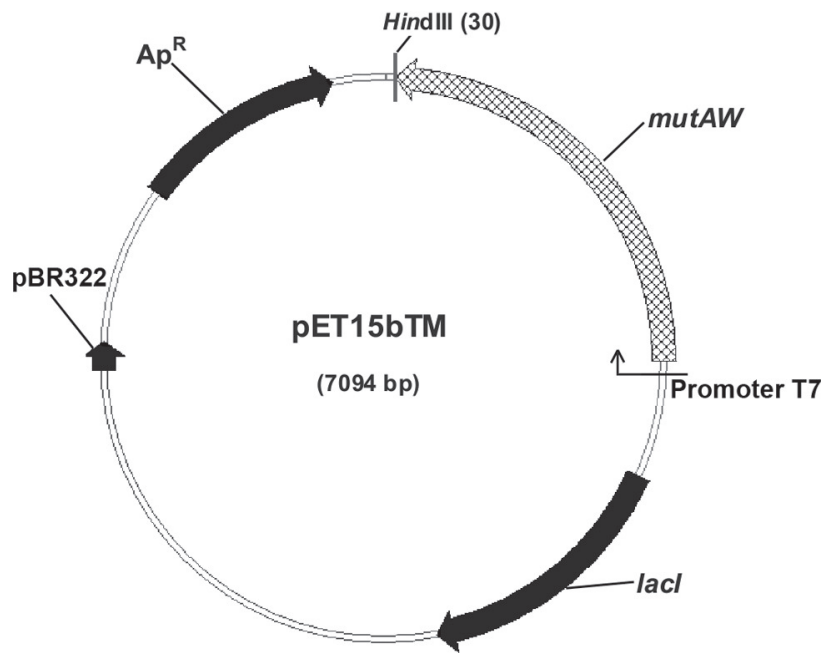

Fig. 4. Schematic diagram of the expression construct pET15bTM containing cDNA of T. harzianum CCM F-340 $m u t A W$ gene without the leader sequence for its signal peptide. 
Table I

Activity of the recombinant $\alpha$-1,3-glucanase of T. harzianum after purification steps

\begin{tabular}{|l|c|c|c|c|c|}
\hline \multicolumn{1}{|c|}{ Purification step } & $\begin{array}{c}\text { Total protein } \\
(\mathrm{mg})\end{array}$ & $\begin{array}{c}\text { Total activity } \\
(\mathrm{U})\end{array}$ & $\begin{array}{c}\text { Specific activity } \\
(\mathrm{U} / \mathrm{mg} \text { protein })\end{array}$ & $\begin{array}{c}\text { Yield } \\
(\%)\end{array}$ & $\begin{array}{c}\text { Fold } \\
\text { purification }\end{array}$ \\
\hline Cell extract & 580 & 21.4 & 0.036 & 100 & 1 \\
\hline DEAE-chromatography & 112 & 10 & 0.089 & 46.7 & 2.5 \\
\hline Size exclusion - chromatography & 40 & 3.9 & 0.097 & 18.2 & 2.7 \\
\hline
\end{tabular}

mutanase naturally produced by the Trichoderma mold is in the form of glycoprotein. Hovewer, the unglycosylated protein demonstrated also mutanase activity. The recombinant protein showed a lower activity at $45^{\circ} \mathrm{C}$ than the native enzyme produced by the fungus (data not shown). This might indicate that proper glycosylation of mutanase is indispensible for the optimal activity of this enzyme. Fuglsang and co-workers (2000) reported that wild-type T. harzianum mutanase displayed a molecular mass of $75 \mathrm{kDa}$, both in SDS-PAGE and MALDI-MS. Carbohydrate composition analysis revealed the presence of glucose and mannose (18 and $32 \mathrm{~mol} / \mathrm{mol}$ enzyme, respectively) that accounted for over $8 \mathrm{kDa}$ of the protein mass. In general, mutanases demonstrate higher sequence similarity in the $\mathrm{N}$-terminal and C-terminal parts of the mature enzymes, and are less conserved in the Pro-Ser-Thr region that is the supposed site for O-glycosylation. Similarly, SerThr-rich linker region of A. niger glucoamylase was demonstrated to be the site for this protein modification (Coutinho and Reilly, 1994). The glycosylation level was sometimes even higher in comparison to the wildtype mutanases, as was described for the T. harzianum

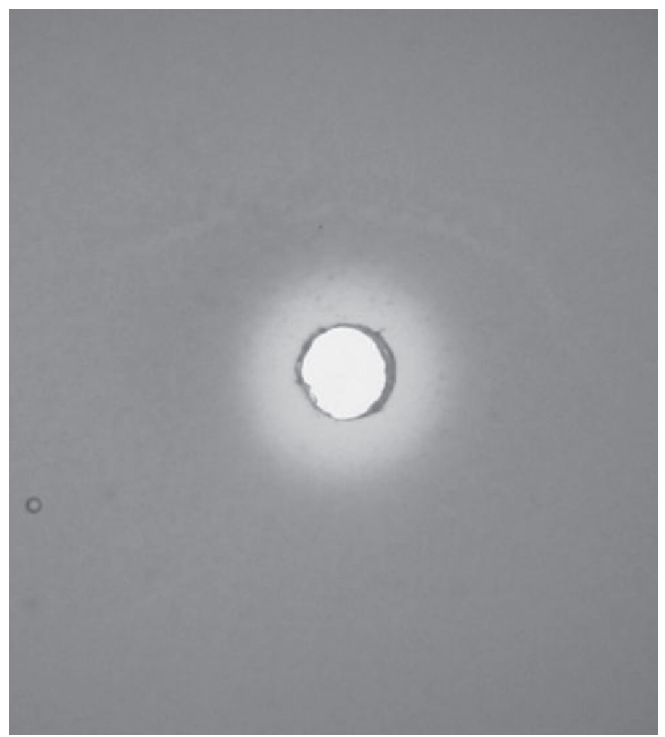

Fig. 5. Mutan-hydrolyzing activity of T. harzianum recombinant $\alpha$-1,3-glucanase.

Mutan hydrolyzing activity was assayed on agar plate containing $0.25 \%$ streptococcal mutan after incubation for 24 hours at $37^{\circ} \mathrm{C}$. The formation of the halo is indicative of mutan hydrolyzing activity. and $P$. purpurogenum recombinant enzymes displaying molecular masses of 86 and $90 \mathrm{kDa}$, respectively, when they were produced in a heterologous expression system in A. oryzae (Fuglsang et al., 2000). The purified enzyme from T. harzianum CECT 2413 was present in the form of $\sim 75 \mathrm{kDa}$ after SDS-PAGE and $132 \mathrm{kDa}$ after gel filtration chromatography. This suggests that this mutanase could be a dimeric protein in solution (Sanz et al., 2005; Ait-Lahsen et al., 2001), in contrast to the tetramer form for another $\alpha$-1,3-glucanase from T. harzianum CCM F-470 (Wiater et al., 2001).

The mutanase $102 \mathrm{kDa}$ from P. purpurogenum CBS 257.37 was probably N-glycosylated and O-mannosylated when generated using Pichia pastoris expression system (Shalom et al., 2008). This data indicated that the use of individual heterologous expression systems offers a number of advantages as well as disadvantages that affect the production of an active enzyme. We observed that extracellular production of T. harzianum CCM F-340 mutanase in the P. pastoris system resulted in its hyperglycosylation, and in effect a complete loss of activity. Removing the N-glycosylation site (NGS) by site directed mutagenesis (change of Asp-360 to Ala-360) also negatively affected the enzyme activity (data not shown). In an E. coli expression system, over-produced proteins often accumulate in the cells in insoluble forms as inclusion bodies, and as a consequence, are often inactive (Shu et al., 2007).

Conclusions. $\alpha-1,3-$ Glucanases (mutanases) have been reported in a number of bacteria, yeasts and fungi, but so far this class of enzymes is a relatively uncharacterized family of proteins. Because of their potential use in the treatment of dental caries, we were interested in the production of the T. harzianum mutanase in E. coli expression systems. For this purpose, the mutanase gene was identified, characterized, and used in the construction of a recombinant plasmid. Our data indicate that the obtained enzyme is conserved in Trichoderma and can be effectively produced in this heterologous expression system.

\section{Acknowledgements}

This work was financially supported from funds for science in the years 2008-2012 as the development project No KB/46/13110/ IT1-B/U/08. 


\section{Literature}

Ait-Lahsen H., A. Soler, M. Rey, J. de la Cruz, E. Monte and A. Llobell. 2001. An antifungal exo- $\alpha(1 \rightarrow 3)$-glucanase (AGN13.1) from the biocontrol fungus T. harzianum. Appl. Environ. Microbiol. 67: 5833-5839.

Bradford M.M. 1976. A rapid and sensitive method for the quantitation of microgram quantities of protein utilizing the principle of protein-dye binding. Anal. Biochem. 72: 248-54.

Budtz-Jörgensen E. and J. Kelstrup. 1977. Enzymes as denture cleansers. Scand. J. Dent. Res. 85: 209-215.

Chung J., H.H. Kim, J.H. Shin, H.C. Lee, Z. Hee Lee and J.S. Oh. 2001. Identification of mutanase-producing Microbispora rosea from the soil of Chonnam Province. J. Microbiol. Biotechnol. 11: 677-684.

Coutinho P.M. and P.J. Reilly. 1994. Structure-function relationships in the catalytic and starch binding domains of glucoamylase. Protein Eng. 7: 393-400.

Ebisu S., K. Kato, S. Kotani and A. Misaki. 1975. Isolation and purification of Flavobacterium a-1,3-glucanase-hydrolyzing, insoluble, sticky glucan of Streptococcus mutans. J. Bacteriol. 124: 1489-1501.

Fuglsang C.C., R.M. Berka, J.A. Wahleitner, S. Kauppinen, J.R. Shuster, G. Rasmussen, T. Halkier, H. Dalbøge and B. Henrissat. 2000. Biochemical analysis of recombinant fungal mutanases. J. Biol. Chem. 275: 2009-2018.

García I., D. Jiménez, V. Martín, A. Durán and Y. Sánchez. 2005. The a-glucanase Agn1p is required for cell separation in Schizosaccharomyces pombe. Biol. Cell 97: 569-576.

Hasegawa S., J.H. Nordin and S. Kirkwood. 1969. Enzymes that hydrolyze fungal cell wall polysaccharides. I. Purification and properties of an endo- $\alpha-\mathrm{D}-(1 \rightarrow 3)$-glucanase from Trichoderma viride. J. Biol. Chem. 244: 5460-5470.

Inoue M., T. Yakushiji, J. Mizuno, Y. Yamamoto and S. Tanii. 1990. Inhibition of dental plaque formation by mouthwash containing an endo- $\alpha-1,3$ glucanase. Clin. Prevent. Dent. 12: 10-14.

Matsuda S., Y. Kawanami, H. Takeda, T. Ooi and S. Kinoshita. 1997. Purification and properties of mutanase from Bacillus circulans. J. Ferm. Bioeng. 83: 593-595.

Meyer M.T. and H.J. Phaff. 1977. Survey for $\alpha-(1 \rightarrow 3)$-glucanase activity among yeasts. J. Bacteriol. 131: 702-706.

Papavizas G.C. 1985. Trichoderma and Gliocladium: biology, ecology, and potential for biocontrol. Annu. Rev. Phytopathol. 23: 23-54.
Pleszczyńska M., M. Marek-Kozaczuk, A. Wiater and J. Szczodrak. 2007. Paenibacillus strain MP-1: a new source of mutanase. Biotechnol. Lett. 29: 755-759.

Reese E.T., A. Maguire and F.W. Parrish. 1972. a-1,3-Glucanases of fungi and their relationship to mycodextranase. Proceedings of the IVth International Fermentation Symposium. Ferment. Technol. Today 735-742.

Sambrook J., E.F. Fritsch and T. Maniatis. 1989. Molecular Cloning; a Laboratory Manual, $2^{\text {nd }}$ ed. Cold Spring Harbor, NY: Cold Spring Harbor Laboratory

Sanz L., M. Montero, J. Redondo, A. Llobell and E. Monte. 2005. Expression of an $\alpha$-1,3-glucanase during mycoparasitic interaction of Trichoderma asperellum. FEBS Journal 272: 1-7.

Schuster A. and M. Schmoll. 2010. Biology and biotechnology of Trichoderma. Appl. Microbiol. Biotechnol. 87: 787-799.

Shalom G., J. Pratten, M. Wilson and S.P. Nair. 2008. Cloning, heterologous gene expression and biochemical characterization of the alpha-1,3-glucanase from the filamentous fungus Penicillium purpurogenum. Protein Expr. Purif. 60: 170-175.

Shu Z.Y., Y.J. Yan, J.K. Yang and L. Xu. 2007. Aspergillus niger lipase: gene cloning, over-expression in Escherichia coli and in vitro refolding. Biotechnol. Lett. 29: 1875-1879.

Viterbo A., O. Ramot, L. Chernin and I. Chet. 2002. Significance of lytic enzymes from Trichoderma ssp. in the biocontrol of fungal plant pathogens. Antonie von Leewenhoek 81: 549-556.

Walker G.J. and M.D. Hare. 1977. Metabolism of the polysaccharides of human dental plaque. Part II. Purification and properties of Cladosporium resinae $(1 \rightarrow 3)$ - $\alpha$-D-glucanase, and the enzymic hydrolysis of glucans synthesized by extracellular D-glucosyltransferases of oral streptococci. Carbohydr. Res. 58: 415-432.

Wei H., M. Scherer, A. Singh, R. Liese and R. Fischer. 2001. Aspergillus nidulans alpha-1,3-glucanase (mutanase), $m u t A$, is expressed during sexual development and mobilizes mutan. Fungal Genet. Biol. 34: $217-227$.

Wiater A. and J. Szczodrak. 2002. Selection of strain and optimization of mutanase production in submerged cultures of Trichoderma harzianum. Acta Biol. Hung. 53: 389-401.

Wiater A., J. Szczodrak and M. Pleszczyńska. 2008. Mutanase induction in Trichoderma harzianum by cell wall of Laetiporus sulphureus and its application for mutan removal from oral biofilms. J. Microbiol. Biotechnol. 18: 1335-1341.

Wiater A., J. Szczodrak and J. Rogalski. 2001. Purification and characterization of extracellular mutanase from Trichoderma harzianum. Mycol. Res. 105: 1357-1363. 